\title{
Political Economy of Regional Trading Arrangements in South Asia
}

\author{
Hemanta K. Shrestha \\ AT\&T Corporation \\ Mukti P. Upadhyay \\ Eastern Illinois University
}

\begin{abstract}
We examine how the factors conventionally found important for trade in other regions of the world influence trade in South Asia. Our gravity model starts by estimating the effects of economic variables such as per capita income and the size of economies on bilateral trade. We then use a novel dataset by extending the model to evaluate the role of non-economic factors such as geography, political cooperation and cultural similarity among nations. We find that the positive effects of incomes and cultural similarity on trade are largely neutralized by adverse political developments that repress trade within the region.
\end{abstract}

- JEL Classification: F15, O57

- Key words: regional trading arrangements, political model, South Asia, gravity model

\section{Introduction}

The resurgence of interest in regional integration in the 1990s has produced a large number of studies evaluating its success and failure in different regions of the world. These studies attempt to measure the welfare effect through potential increase or decrease in regional trade following integration. The framework used

*Corresponding address: Hemanta K. Shrestha, Economist, AT\&T Corporation, Basking Ridge, NJ 07920, Email: shrestha@att.com, Mukti P. Upadhyay, Associated Professor, Department of Economics, Eastern Illinois University Charleston, IL 61920, USA, Tel: 217-581-3812, Fax: 217-581-5997, E-mail: cfmpu@eiu.edu (C2004-Center for International Economics, Sejong Institution, All Rights Reserved. 
helps assess how much the elimination of trade barriers is likely to boost trade in the region and beyond. In order to separate the effects of other factors from those of integration, a typical model controls for important variables such as income, level of development, resource endowment, and the geographical structure of countries.

A vast majority of empirical studies on regional trading arrangements focus only on economic variables and ignore the role of socio-cultural and political factors in trade. Yet, both these sets of variables can and often do have a significant role to play in trade. Importers consider not only product quality and prices but also the place of product origin and political relations with the exporting country. Similarly, exporters may be concerned about the place of destination and about political relations. Traders may avoid establishing ties with their counterparts in an adversary country, knowing that such ties may be ruptured by one government or the other as part of some foreign policy maneuver (Pollins, 1989). Further, consumers may, through market behavior, wish to express goodwill or solidarity toward those exporting countries they identify as friends and to punish those they perceive as foes. Thus, a lack of political cooperation and commitment between countries can seriously threaten the viability of a regional integration scheme.

In 1994, a group of countries in South Asia-Bangladesh, Bhutan, India, Maldives, Nepal, Pakistan, and Sri-Lanka-formed South Asian Preferential Trading Arrangement (SAPTA). The initial goal was to establish a free trade area by 2005 . SAPTA began with a first round of tariff cuts on 226 goods. Later, at a 1997 summit, the target date for a free trade zone was advanced to 2001. Yet, despite initial enthusiasm, and apparently significant trade potential in the region, SAPTA has not made much progress toward eliminating tariff and non-tariff barriers to trade. The intra-regional trade barely increased from 3\% in 1993 to $3.8 \%$ in 1996 (IMF, 1998).

This dismal performance has raised questions about any noneconomic factors that may have repressed trade expansion in South Asia. One apparent obstacle is hostility between India and Pakistan, the two economic giants in the region. Following their separation in 1947, these two countries emerged as military rivals and almost completely ignored economic opportunities and benefits of greater cooperation. Moreover, their recent test of nuclear weapons in 1999 seems to have seriously threatened the viability of SAPTA and the security of the entire region.

Notwithstanding political threat to SAPTA, the economic potential gives some 
hope. When, for instance, we correct the low intraregional trade ratio by a measure of SAPTA's importance in world trade, we find that the region trades more within than with the rest of the world. The corrected concentration ratio, which equals intraregional trade as a fraction of members' total trade divided by members' total trade as a fraction of total world trade, is greater than 1. This ratio was 1.123 in 1994, and rose to 1.587 in 1995 . Such official indicators must be supplemented further by informal trade that exists on a significant scale between countries due to large tariff and non-tariff barriers.

The objective of this study is to measure the impact of both economic and noneconomic factors on trade flows in South Asia. Along with conventional economic variables such as income, population, and distance, this study evaluates to what extent policy-induced distortions-primarily trade policy, exchange rate control, and political cooperation or conflicts-have influenced intraregional trade. We examine a modified gravity model to explore whether the factors conventionally found important in other regions influence trade in similar ways and to a significant degree in South Asia as well.

\section{The Model}

The classic gravity equation offers a systematic framework for measuring the "normal" pattern of bilateral trade. The goal is to see to what extent trade within each region can be explained by "natural" economic factors, such as gross national product that proxies for the size of the economy, per capita income which represents the level of development, population of countries and distance between them. ${ }^{1}$

Income, distance, and population are the most common variables included in empirical estimates of the gravity equation. These variables have a direct and significant impact on trade flows between countries. Most empirical studies show that income and population affect trade flows positively and significantly while

Tinbergen (1962) introduces the gravity model to international economics to analyze regional trade. Anderson (1979) and Bergstrand (1985), among others, provide theoretical foundation for the gravity equation. Anderson (1979) derives a gravity equation by adopting a linear expenditure system where preferences are homothetic and uniform across importing countries. Bergstrand (1985) assumes constant elasticity of substitution preferences and a general equilibrium framework of world trade that yield a reduced form equation for bilateral trade. Helpman and Krugman (1985) find that the gravity equation closely tracks bilateral trade data and provides firm support for their monopolistic competition model. Finally, Deardorff (1997) shows how the standard Heckscher-Ohlin model can be used to derive a simple gravity equation. Among empirical studies, a pioneering work was done by Linnenman (1966). 
physical distance between trading nations that proxies for transportation cost has a significant negative impact. Studies also show that regional trading blocs have a positive effect on bilateral trade among members.

A major study of bilateral trade within and across trade blocs was conducted by Frankel, Stein, and Wei, (1997). They examine the existing trade patterns throughout the world, but find different magnitudes and trends of the bloc effects for different parts of the world. Their study shows the strongest effects of regional blocs for the Association of Southeast Asian Nations (ASEAN), and Mercado Común del Sur (MERCOSUR) as compared to other blocs, and suggests that the expansion of European Community in 1973 and 1983 boosted intra-EC trade by $65 \%$.

Beyond the most basic variables discussed above, some gravity models estimate the impact of trade policy, such as tariff rate, black market exchange premium, and direct exchange control. And finally, to explore the noneconomic roots of regional integration schemes, some of the more modern studies seek to determine the effect on trade of political and cultural factors as well.

Given the significant role that politics seem to have played in constraining trade within South Asia, we extend the classical gravity model to allow for several other variables such as trade policy, political cooperation, and cultural similarity. The general form of the gravity equation in our study is

$T_{i j}=f\left(\right.$ PERCAP $_{i}$, PERCAP $_{j}, G_{N} P_{i}, G N P_{j}$, DISTANCE, $\left.B L K P R M_{i}, B L K P R M_{j}, T A R_{i}, T A R_{j}, P O L, C U L\right)$

where,

subscripts $i$ and $j$ represent countries

$T_{i j}=$ Exports from country $i$ to country $j$ in constant 1987 US dollars

PERCAP = Per capita income (GNP divided by population) in 1987 US dollars

$G N P=$ Gross National Product in 1987 US dollars

DISTANCE $=$ Geographical distance between two closest cities of countries $i$ and $j$ with population over 100,000

$T A R=$ Average tariff rate

$B L K P R M=$ Black market exchange rate premium

$P O L=$ Political relations between two countries

$C U L=$ Cultural similarity between two countries

\section{A. Variables and data:}

Our dependent variable, the trade flow $\left(T_{i j}\right)$, is the value of exports from country 
$i$ to country $j$ in a given year. Of the income variables in equation (1), PERCAP reflects the level of development, and GNP measures the total purchasing power of citizens or overall market size of countries. These measures are adjusted to ensure purchasing power parity of the U.S. dollar across countries. Our DISTANCE variable proxies for transportation cost and geographical proximity. The conventional way to construct this variable is to measure the distance between capital cities of the countries concerned. In South Asia, however, India is physically much larger than all other countries combined. It borders with Bangladesh, Nepal, and Pakistan and is only separated from Sri Lanka by a narrow Park Strait. The location of its capital New Delhi in the northwest of the country thus poses a problem for the measurement of distance between India and other countries. For our distance variable, therefore, we take instead the distance between the two closest cities that have population over one hundred thousand.

The tariff rates of a country usually differ by product category and exporting country. In the absence of tariff data disaggregated by product and trading partner, however, our TAR for a country represents the average realized rate of tariff, that is, total tariff revenue divided by that country's total imports. Another trade policy variable we use is BLKPRM which measures percentage difference between the dollar's official exchange rate and its black market rate.

Among noneconomic variables, we include political relations and cultural similarities. The net political cooperation variable, $P O L$, measures the overall nature and extent of political interaction between countries. The political interaction variable is based on event data from World Event Interaction Survey (WEIS) that covers 243 nations and non-state actors and is based on Reuters news reports as published in The New York Times. This annual time series measures the extent of cooperation or conflict implicit in a series of actions taken by one nation toward another. To construct a measure of conflict and cooperation between countries, we follow Goldstein (1992) and develop a procedure to assign different weights to all the listed 61 WEIS events ranging from +10 to -10 . The higher weights represent greater cooperation and lower weights represent greater conflict between countries. Among the cooperative events are bilateral treaties and agreements, establishment of bilateral relations, and increases in grants and aid between countries. The "conflictual" events include discontinuation of aid, closing of borders, a war and so on. A score of 0 implies no change in the current policy and -10 represents a "military attack." The description and weights for events appear in Appendix I. 
We accessed the WEIS events data for South Asia from Kansas Event Data Systems (KEDS, 1999) which covers the period 1984-1994. Events data are superior to dummy variables since they measure the degree and intensity of political interaction between countries. Table 1 presents the net political cooperation variable for the South Asian countries over the period 1984-1994.

The net political cooperation between a pair of countries is a weighted value of events indicating both conflict and cooperation. The sign and magnitude of the net cooperation variable depend on the number and types of events that occurred between the countries during any given year. Table 1 shows the weighted value of net political cooperation for each year. A larger negative value suggests strained or hostile political relations, and a larger positive value indicates more friendly relations between countries. Similarly, a value of zero indicates either no major political interaction, or strongly positive and negative interactions that simply happen to cancel out. Inclusion of this variable in the gravity equation measures the extent to which change in political relations between countries affects trade flows between them.

The construction of the cultural variable, $C U L$, is based on religious similarity among countries. Table 2 presents the distribution of religion in South Asia. It shows that people in Bangladesh and Pakistan are predominantly Muslim, while most people in India and Nepal are Hindu. In Sri Lanka, over two-thirds of the population are Buddhist.

The cultural variable represented by religion reflects commonality among the member countries. For each pair of South Asian countries, we construct the

Table 1. Net Political Cooperation in South Asia (1984 -1994)

\begin{tabular}{lccccccccccc}
\hline & 1984 & 1985 & 1986 & 1987 & 1988 & 1989 & 1990 & 1991 & 1992 & 1993 & 1994 \\
\hline Ban-Ind & -18.9 & -5.8 & -23.3 & -14 & -13.8 & 0.8 & -2 & -0.7 & -0.4 & 00 & 0.2 \\
Ban-Nep & 00 & 00 & 33.9 & -6.9 & -4.4 & 00 & 00 & 00 & 00 & -0.2 & 00 \\
Ban-Pak & 00 & 00 & 00 & 77.4 & 00 & 33.8 & 00 & 00 & 00 & 00 & 00 \\
Ban-Sri & 00 & 11 & 00 & -0.2 & 00 & 00 & 00 & 00 & 00 & 00 & 00 \\
Ind-Nep & 00 & -0.4 & 88.3 & 00 & 00 & -17.7 & -8.1 & 00 & 00 & 00 & 00 \\
Ind-Pak & -72.4 & -35 & -45 & -35 & 112.5 & -19.6 & -54.6 & -95.8 & -41.9 & -29.8 & -68.4 \\
Ind-Sri & -17.2 & -21.3 & -26.9 & -57.5 & -11.1 & -14.6 & -3.3 & -31.5 & -4.6 & 00 & 00 \\
Nep-Pak & 00 & 00 & 00 & 00 & 00 & 00 & 00 & 00 & -7.2 & 00 & 00 \\
Nep-Sri & 00 & 00 & 00 & 00 & 00 & 00 & 00 & 00 & 00 & 00 & 00 \\
Pak-Sri & 00 & -5.7 & 00 & 00 & 00 & 00 & 00 & 00 & 00 & 00 & 00 \\
\hline
\end{tabular}

Note: Ban: Bangladesh; Ind: India; Nep: Nepal; Pak: Pakistan; Sri: Sri Lanka 
Table 2. Distribution of Religious Preferences in South Asia (percentages)

\begin{tabular}{lccccc}
\hline \multicolumn{1}{c}{ Religion } & Bangladesh & India & Nepal & Pakistan & Sri Lanka \\
\hline Hindu & 12.13 & 82.6 & 90.0 & 1.5 & 15.0 \\
Muslim & 86.6 & 11.4 & 1.0 & 96.7 & 7.5 \\
Christians & 0.31 & 2.4 & 0.5 & 1.55 & 7.5 \\
Sikhs & - & 2.0 & - & 0.12 & - \\
Buddhists & 0.61 & 0.7 & 7.0 & 0.008 & 70 \\
Jains & - & 0.5 & - & 0.002 & - \\
Others & 0.28 & 0.4 & 1.5 & 1.19 & - \\
\hline
\end{tabular}

Source: Ahmed (1996).

variable by first taking the lower of the two percentage shares for any given religion. We then add all the minimum values across religions to represent the cultural commonality among countries. Thus, we compute the values for cultural commonality among any two countries $i$ and $j$ as follows:

where,

$$
C U L_{i j}=\sum_{\mathrm{x}} \min \left(S_{i}^{X}, S_{j}^{X}\right)
$$

$$
\begin{aligned}
& S_{i}^{X}=\text { Share of religion } x \text { in country } i \\
& S_{j}^{X}=\text { Share of religion } x \text { in country } j
\end{aligned}
$$

The theoretical maximum for $C U L$ is 100 and the minimum is 0 . The computed values of cultural commonality are: 20.55 between Bangladesh and Sri Lanka, 88.69 between Bangladesh and Pakistan, 14.98 between India and Pakistan, 85.2 between India and Nepal.

We use panel data for five South Asian countries: Bangladesh, India, Nepal, Pakistan, and Sri Lanka. Because of data limitations, we exclude two countries in SAPTA, Bhutan and the Maldives, from the analysis. Our three distinct specifications for the gravity model are as follows:

$$
\begin{aligned}
& \log \left(T_{i j}\right)=\alpha_{0}+\alpha_{1} \log \left(P E R C A P_{i}\right)+\alpha_{2} \log \left(P E R C A P_{j}\right)+\alpha_{3} \log \left(G N P_{i}\right) \\
& +\alpha_{4} \log \left(G N P_{j}\right)+\alpha_{5} \log (\text { DISTANCE })+u_{i} \\
& \log \left(T_{i j}\right)=\beta_{0}+\beta_{1} \log \left(\text { PERCAP }_{i}\right)+\beta_{2} \log \left(\text { PERCAP }_{j}\right)+\beta_{3} \log \left(G N P_{i}\right) \\
& +\beta_{4} \log \left(\text { GNP }_{j}\right)+\beta_{5} \log (\text { DISTANCE })+\beta_{6} \log \left(\text { TAR }_{i}\right) \\
& +\beta_{7} \log \left(T A R_{j}\right)+\beta_{8} \log \left(B L K P R M_{i}\right)+\beta_{9} \log \left(B L K P R M_{j}\right)+\pi_{I} \\
& \left.\log \left(T_{i j}\right)=\gamma_{0}+\gamma_{1} \log \left(P E R C A P_{i}\right)+\gamma_{2} \log \left(P E R C A P_{j}\right)+\gamma_{3} \log \left(G N P_{i}\right)+\gamma_{4} \log G N P_{j}\right)
\end{aligned}
$$




$$
\begin{aligned}
& +\gamma_{5} \log \left(\text { DISTANCE }+\gamma_{6} \log \left(\text { TAR }_{i}\right)+\gamma_{7} \log \left(\text { TAR }_{j}\right)+\gamma_{8} \log \left(\text { BLKPRM }_{i}\right)\right. \\
& +\gamma_{9} \log \left(B L K P R M_{j}\right)+\gamma_{10}(P O L)+\gamma_{11} \log (C U L)+v_{I}
\end{aligned}
$$

Equation 3 represents the simplest gravity model relating bilateral trade to income and distance variables. Higher GNP and per capita income are likely to enhance trade flows whereas greater distance between countries is expected to reduce them as countries will probably trade more with geographically closer partners than with more distant ones.

Equation 4 extends equation 3 by adding average tariff rate, $T A R$, and black market exchange rate premium (BLKPRM) to capture the impact of trade policy and foreign exchange control. An increase in a country's own TAR will reduce its imports (that is, other's exports to it). But it may or may not change its exports to others.

BLKPRM is expected to be related inversely to a country's exports and positively to its imports. A larger deviation of official exchange rate (dollar's value in terms of domestic currency) from the equilibrium rate indicates greater overvaluation of the local currency which is likely to decrease the country's exports but produce an ambiguous effect on the importing country. An increase in black market premium in country $i$ should also increase $i$ 's imports but its effects on the exports of country $j$ would be ambiguous.

Equation 5 is more comprehensive than equation 4 in that it helps examine the effects of political interaction and cultural similarity as well. This last specification captures the impact of both policy-induced distortions and non-policy factors on regional trade. The policy-induced distortions are reflected in tariff rates, exchange rates, and political interactions between countries. To the extent these factors have a large and significant influence on trade flows, SAPTA will expand trade in the region through reductions in tariffs and non-tariff barriers and better alignment of exchange rates. The non-policy induced variables include income, distance, and cultural factors.

In equation 5, all the explanatory variables appear in logarithms except net political cooperation which is specified in the original level form since it can assume non-positive values. Greater political cooperation (i.e., a rise in $P O L$ ) is likely to result in lower trade barriers and larger volume of trade. Analogously, greater cultural similarity (a rise in $C U L$ ) should also enhance trade through convergence of tastes and preferences.

\section{B. Data Sources:}

We use pooled time-series cross-country data set that has 220 observations consisting of 20 bilateral trade flows per year for 11 years (1984-1994). Data for the 
dependent variable $T_{i j}$, that is, the exports of country $i$ to country $j$, were collected for the sample period 1984-94 from Direction of Trade Statistics (IMF, various issues). Penn World Table provided data on per capita income and population. For distance between countries, measured in kilometers, we used Direct Line Distances: International Edition (Fitzpatrick, 1986). Data for the black market exchange rate premium, BLKPRM, came from World Currency Yearbook (IMF, various issues). To construct the tariff rate variables, $T A R_{i}$ and $T A R_{j}$, the volume of total imports and the total import revenues of each country were available from Government Finance Statistics Yearbook (IMF, 1997). Finally, as mentioned earlier, WEIS events data yielded a measure of net political cooperation, $P O L$, whereas the cultural variable $C U L$ was proxied by the distribution of religion among countries and was due to Ahmed (1996).

\section{Model Estimation and Results}

Results of the estimated model appear in Table 3. Broadly speaking, the coefficients on the explanatory variables in all three versions of the model have the expected signs. However, the magnitude and level of significance of the coefficients vary with model specification.

Per Capita Income: The estimated coefficients on the income variables are positive and highly significant for all specifications. On average, the coefficients for $P E R C A P_{i}$, suggest that a $1 \%$ increase in per capita income of the exporting country $i$ results, ceteris paribus, in a $0.65 \%$ increase in its exports to the importing country $j$. Income growth due to increased productivity of workers, for instance, will strengthen a country's export competitiveness and raise its share in world exports. Such growth in productivity could occur as increases in per capita income shift the production structure of developing countries from agriculture toward manufacturing and services (Chenery and Syrquin, 1975). The stylized fact that trade increases with the level of development is thus verified for South Asia as well.

Similarly, per capita income of the importing country, $P E R C A P_{j}$, has a positive and highly significant influence on trade flows. We find that on average import demand within South Asia is unitary elastic with respect to importing country's per capita income.

Our estimates seem reasonable. The literature on trade blocs indicates that the benchmark coefficients for per capita income range from 0.28 to 0.99 (Frankel, 
Table 3. The Results

\begin{tabular}{|c|c|c|c|}
\hline VARIABLES & Equation 3 & Equation 4 & Equation 5 \\
\hline CONSTANT & $\begin{array}{c}-27.636 * * * \\
(-7.509)\end{array}$ & $\begin{array}{c}-27.578 * * * \\
(-6.742)\end{array}$ & $\begin{array}{c}-28.134 * * * \\
(-7.962)\end{array}$ \\
\hline PERCAP $_{\mathrm{I}}$ & $\begin{array}{l}0.522 * \\
(1.586)\end{array}$ & $\begin{array}{c}0.795 * * * \\
(2.530)\end{array}$ & $\begin{array}{c}0.658 * * * \\
(2.421)\end{array}$ \\
\hline PERCAP $_{\mathrm{j}}$ & $\begin{array}{c}0.842 * * * \\
(2.596)\end{array}$ & $\begin{array}{c}1.161 * * * \\
(3.761)\end{array}$ & $\begin{array}{c}0.909 * * * \\
(3.386)\end{array}$ \\
\hline $\mathrm{GNP}_{\mathrm{I}}$ & $\begin{array}{c}0.815 * * * \\
(12.931)\end{array}$ & $\begin{array}{c}0.616^{* * * *} \\
(5.574)\end{array}$ & $\begin{array}{c}0.627 * * * \\
(6.477)\end{array}$ \\
\hline $\mathrm{GNP}_{\mathrm{j}}$ & $\begin{array}{c}0.356 * * * \\
(5.626)\end{array}$ & $\begin{array}{c}0.365^{* * * *} \\
(3.305)\end{array}$ & $\begin{array}{c}0.403 * * * \\
(4.138)\end{array}$ \\
\hline DISTANCE & $\begin{array}{c}-0.179 * * * \\
(-2.260)\end{array}$ & $\begin{array}{c}-0.274 * * * \\
(-3.618)\end{array}$ & $\begin{array}{c}-0.075 \\
(-1.081)\end{array}$ \\
\hline $\mathrm{TAR}_{\mathrm{I}}$ & - & $\begin{array}{c}0.539 * * \\
(1.835)\end{array}$ & $\begin{array}{c}0.740 * * * \\
(2.90)\end{array}$ \\
\hline $\mathrm{TAR}_{\mathrm{j}}$ & - & $\begin{array}{c}-0.089 \\
(-0.303)\end{array}$ & $\begin{array}{c}0.033 \\
(0.132)\end{array}$ \\
\hline $\mathrm{BLKPRM}_{\mathrm{I}}$ & - & $\begin{array}{c}-0.198 * * * \\
(-2.235)\end{array}$ & $\begin{array}{c}-0.229 * * * \\
(-3.164)\end{array}$ \\
\hline BLKPRM $_{j}$ & - & $\begin{array}{c}-0.105 \\
(-1.237)\end{array}$ & $\begin{array}{c}-0.175 * * * \\
(-2.386)\end{array}$ \\
\hline POL & - & - & $\begin{array}{c}0.0297 * * * \\
(4.009)\end{array}$ \\
\hline CUL & - & - & $\begin{array}{c}0.530 * * * \\
(6.847)\end{array}$ \\
\hline $\mathrm{R}^{2}$ & 0.577 & 0.645 & 0.739 \\
\hline Adjusted. $\mathrm{R}^{2}$ & 0.566 & 0.630 & 0.725 \\
\hline
\end{tabular}

The numbers in parentheses correspond to t-statistics.

****significant at $1 \%$ level.

**significant at $5 \%$ level.

* Significant at $10 \%$ level.

The significance levels are based on one-tailed tests.

Stein, and Wei, 1997). From this perspective, growth of per capita income in the SAPTA region is likely to increase trade within the region to a somewhat greater extent than is typical.

Gross National Product: The size of South Asian economies also matters for trade volume. We find that, on average, country $i$ 's exports to $j$ increase by 0.62 percent as $i$ 's GNP grows by 1 percent, and by 0.40 percent in response to $j$ 's GNP growth of 1 percent. Frankel, Stein, and Wei $(1995,1997)$ estimate export elasticities with respect to own and foreign incomes to be around 0.9 and 0.7. South Asia thus 
lags behind other regional groupings in how trade responds to national and regional economic expansion.

The overall results from income variables show that per capita income has somewhat larger influence on trade than does GNP, suggesting the level of develop-ment is more important than country size for trade flows.

Distance: A country is likely to trade more with nearby trading partners than with more distant ones. This prediction comes true for SAPTA. On average, the distance coefficient is -0.2 indicating a much smaller effect of geographical proximity on trade than the benchmark range of -0.45 to -0.75 reported by Frankel, Stein, and Wei (1997).

This low explanatory power of distance in South Asian trade can be largely attributed to the trade between India and Pakistan. Despite close proximity and large size of their economies, their bilateral trade accounts for only 1.32 percent of their total world trade (IMF, 1998). Frankel, Stein, and Wei (1995) argue that trade between India and Pakistan is 70 percent lower than what their model predicts for countries with economic size of, and geographical proximity between, India and Pakistan. Distance, however, seems to assume a more prominent role in $\operatorname{trade}^{2}$ when the model is extended to include trade policies-tariff rate, and the black-market exchange rate premium. On the other hand, when political and cultural variables are also included, the coefficient of distance becomes statistically insignificant.

Trade Policy: We find mixed results about the way trade policy influences regional trade in South Asia. The exporting country's own import tariff, TAR $R_{i}$, shows a positive and significant effect on its exports in equations 4 and 5 . This result may look counterintuitive since an increment in import tariff may have no direct relevance for the country's exports. Further, by switching resources to import substitution, such a policy can reduce the country's exportable surplus. Yet, an increased protection could also stimulate overall domestic production sufficiently for the country to emerge as a net exporter over time. In particular, if restrictive tariffs go along with an export promotion strategy that the partners do not retaliate against, the country's exports may expand. With respect to the partner country's tariff rate, $T A R_{j}$, however, we find positive but insignificant effects on a country's exports, as the results for equations 4 and 5 indicate. To some extent, this reflects the fact that our TAR variables are the average realized rates rather than country-specific tariffs and non-tariff barriers such as quotas, voluntary export restraints, and licensing requirements.

\footnotetext{
${ }^{2}$ Its coefficient rises in absolute terms from -0.179 in equation 3 to -0.274 in equation 4.
} 
The coefficients on the black market exchange rate premium in equations 4 and 5 have negative signs, as expected, and are significant at 1 percent level. They suggest that a 1 percent increase in the exporting country's black market premium is likely to reduce its exports typically by 0.2 percent, indicating an adverse effect of currency overvaluation on exports. Although small as compared to - 0.76 estimated by Laurel and Mutunga (1993) for all LDCs and DCs, the detrimental nature of the effect seems reasonable, since exchange control is commonly used to assist the fixed rate system practiced in SAPTA. The elasticity of exports with respect to the black market premium in the importing country, $B L K P R M_{j}$, is also negative (0.17 ), and is comparable to Laurel and Mutungas estimate of -0.13 , suggesting some region-wide effects of a country's exchange rate policy.

Political cooperation and conflict: We explore the effects of our two political and cultural variables on trade among SAPTA countries. Starting with net political cooperation, $P O L$ in equation 5 , we find that the elasticity of bilateral trade with respect to net political cooperation among countries equals $1.03 .^{3}$ The size of the effect of politics is much larger than, for instance, 0.342 that Pollins (1989) had found, albeit for other regions and for a different sample period.

The significant impact of politics in South Asia mainly shows the huge potential for trade expansion in the region, if political relations were to improve among the SAPTA members. This also indicates that India has a large role to play in the region given its central location in South Asia and its significant trade with every other country. Yet, severe constraints on trade with India have been much too conspicuous in the region. Major conflicts between India and other countries during our sample period include the continued military rivalry between India and Pakistan, the border conflict between India and Bangladesh in 1984, the trade and transit disputes between Nepal and India in 1989, and major disagreements between India and Sri Lanka during 1989 over the Tamil independence issue in Sri Lanka.

Figures 1 through 4 illustrate the relationship between political interaction and bilateral trade among the SAPTA countries over 1984-94. The net political cooperation in South Asia ranges from +12 to -95 during the sample period. A large negative number suggests markedly deteriorating relation and a large positive number suggests more friendly relation. A value close to zero suggests no major political interaction either way.

${ }^{3}$ Because the dependent variable is specified in logarithmic form but the $P O L$ variable is not, we raise the base of the (natural) logarithm to our coefficient (0.0297) of POL. 
Figure 1 shows that, except in 1986, the net political cooperation and the bilateral trade flows between India and Bangladesh tended to move together, both showing a positive trend. Mid-1980s witnessed incidents between India's Border Security Force (BSF) and the Bangladesh Rifles following India's attempt to tighten illegal immigration at the border. During the military regime, Bangladesh attempted to develop a closer relationship with Pakistan to reduce Indian influence and create Islamic republic (Hewitt, 1997). Trade increased between India and Bangladesh, but at a modest rate. The return of civilian government in Pakistan in 1988 and the parliamentary election in Bangladesh in 1990 not only ended the military ties between them, but also brought Bangladesh closer to India. The figure shows that normalization of the political relationship between Bangladesh and India since 1990 has increased their bilateral trade substantially.

Figure 2 illustrates trade and politics between India and Nepal. It shows that, except in 1989 and 1990, the net political cooperation remained close to zero implying no major change in political cooperation or conflict. During 1989-90, the net political cooperation attained a low point of -7.9 when India refused to renew the treaty allegedly because of Nepal's purchase of arms from China in 1988. India also accused Nepal of denying work permits to Indian residents and of failure to deal with the problems of smuggling and the re-exporting of third country

Figure 1. Politics vs. Total Trade INDIA-BANGLADESH

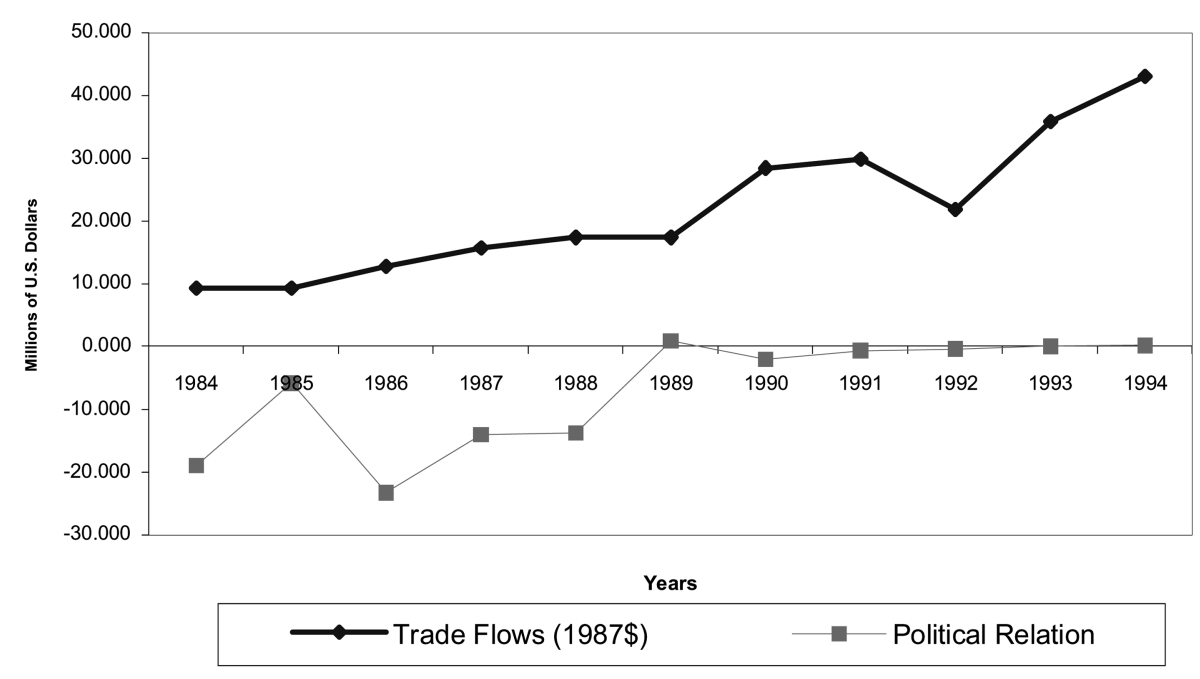

${ }^{4}$ High import barriers in India on goods from third countries provided, especially before 1991, huge incentives to engage in illegal re-exporting to India through Nepal. 
Figure 2. Politics vs Total Trade INDIA-NEPAL

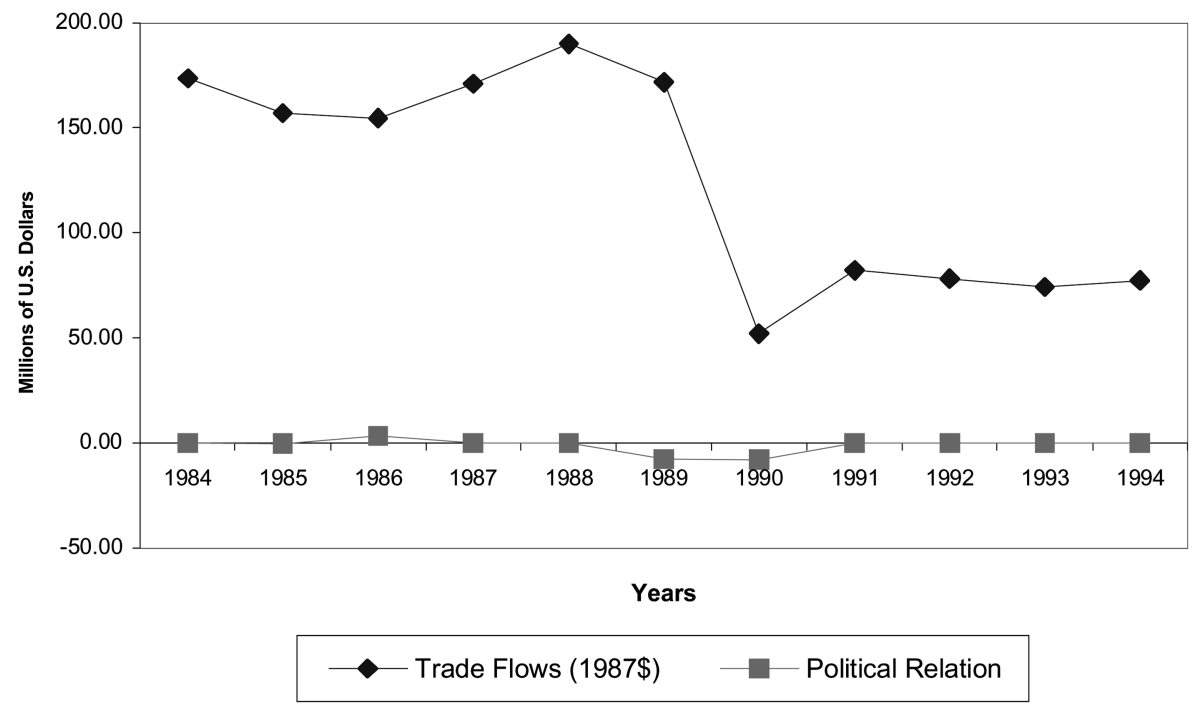

products to India. ${ }^{4}$ The consequent closing by India of all but two of the fifteen trade crossings at the border caused significant hardships on Nepal, a landlocked country which could not much export or import goods through Indias ports in that year. Following the advent of democracy in Nepal in 1991, however, the trade and transit treaty with India was renewed causing significant trade expansion in the following years.

Figure 3 examines the relationship of politics with trade between India and Pakistan

Figure 3. Politics vs Total Trade INDIA-PAKISTAN

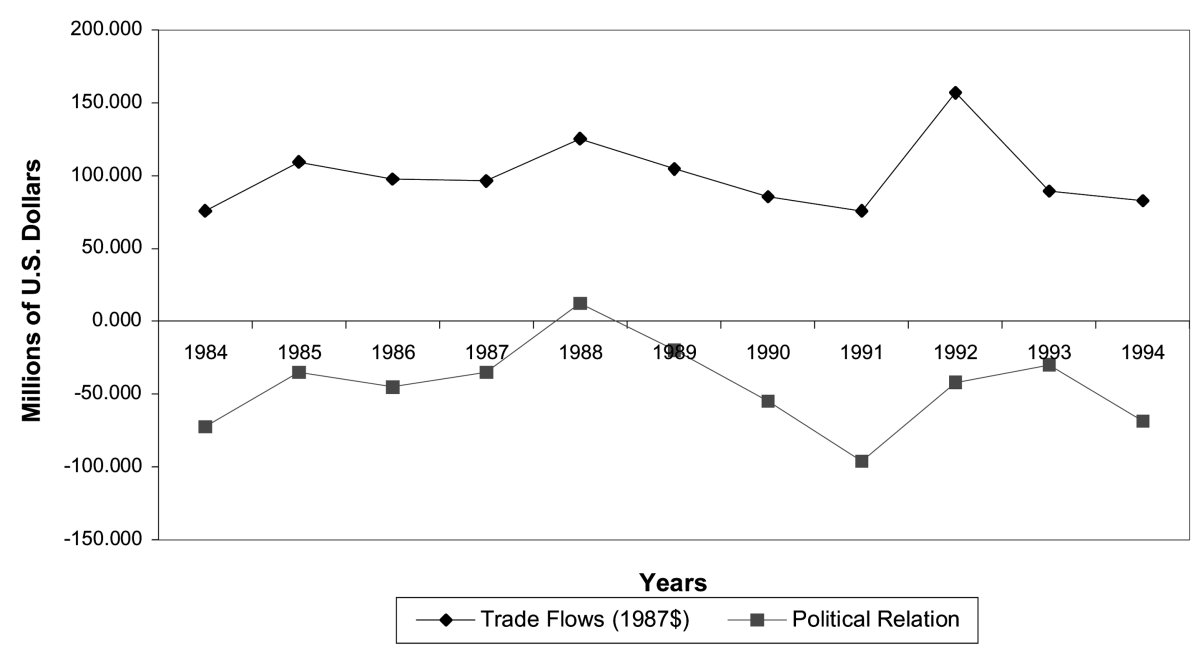


over 1984-94. It clearly shows a high correlation of these countries' bilateral trade with changes in political relations. Minor annual fluctuations apart, the volume of trade shows no trend in the face of rising GDP, depressing the bilateral trade-GDP ratio further. Political relations between India and Pakistan have remained mostly antagonistic and the magnitude of conflict between them relatively high. The countries have deployed nuclear weapons and have occasionally fought small battles over Kashmir. Between 1980 and 1990, Indias defense expenditure increased by $250 \%$ which made the country one of the largest importers of weapons in the world. In turn, Pakistan earned the distinction of setting the highest defense budget in the region in per capita terms (Hewitt, 1997).

The countries have occasionally attempted some easing in their relationship. In 1985, they agreed not to attack each other's nuclear installations, and to join other countries in the formation of SAARC. Some increase in trade also occurred later in the 1990s as a result of market reform and trade liberalization that both countries pursued. Yet, these events have failed to boost trade on a more permanent basis. ${ }^{5}$

Finally, figure 4 shows how trade and politics have evolved between India and Sri Lanka over the period 1984-1994. The figure shows that political interactions between India and Sri Lanka remained mostly negative during the period. Ethnic violence in Sri Lanka between the Tamil minority and Sri Lankan army adversely affected the relations between India and Sri Lanka during much of the1980s. Relations

Figure 4. Politics vs Total Trade INDIA-SRILANKA

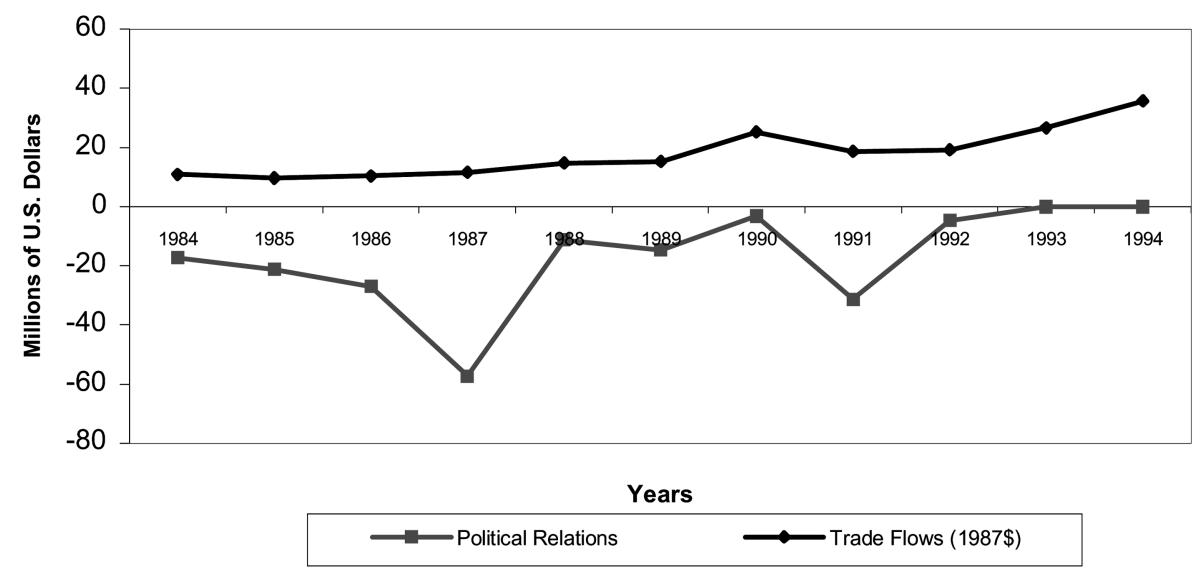

${ }^{5}$ Military tensions have continued to plague Indo-Pak economic relations into the new millennium. The attack on India's parliament building on December 13, 2001 by Kashmiri separatist forces allegedly operating from Pakistan is likely to reduce regional cooperation even further. 
temporarily improved after a 1987 agreement that called for Indian military assistance to solve the "Tamil problem" but the event was later followed by India's withdrawal. Indian support in 1991 to Sri Lankan approach to the Tamil problem has had favorable impact on political cooperation as well as bilateral trade between the two countries since 1992.

The nature of political and trade relations between India and other South Asian countries suggests that political factors have adversely affected trade flows in the SAPTA region. The predominant influence of India and Pakistan in all regional matters, coupled with adverse political relations between them, seems to have denied any significant progress on regional integration in South Asia.

Culture: Finally, we use religious similarity among countries, for lack of a better variable, to represent cultural proximity. Our cultural coefficient is statistically significant and implies that countries with a similar culture are likely to trade $53 \%$ more than the countries with dissimilar cultures. For countries in South Asia that share language, culture, and religion, the pattern of consumption is more similar, and trade contacts more natural. Pakistan and Bangladesh have overwhelmingly large Muslim populations. Their bilateral trade did not suffer major setbacks despite their bloody separation in 1971. India and Nepal, with their predominantly Hindu populations, are also similar in many respects including their consumption pattern.

The overall results from our gravity model suggest that, along with income, distance, and trade policy, political and cultural variables also help explain regional trade in South Asia. While incomes of the exporting and importing countries have a significant impact on South Asian trade, the impact of distance is relatively small. Similarly, while the average tariff rate does not affect trade significantly, another proxy of trade policy, the black market exchange rate premium, has a significant influence on trade, indicating that foreign exchange control discourages intraregional trade as well. ${ }^{6}$

\section{Summary and Conclusion}

Despite their proximity and similar economic structures, international trade

\footnotetext{
${ }^{6}$ As India strives for greater economic openness in the face of poor growth performance of other countries in South Asia, it has sought to develop better trade relations with South East Asian nations. While such a move may induce other SAARC countries to push for greater outward orientation, it is likely to slow the development of SAARC into a free trade area over a short to medium run.
} 
among South Asian countries is unnaturally small. In addition, a dismal performance in trade since its inception has posed serious questions about the viability of SAPTA and its potential to fuel overall economic growth in the region.

The estimated results from the gravity equation suggest that incomes of trading partners, and policy-induced economic distortions significantly influence trade. The impact of distance on trade is rather small. More important is currency overvaluation which has significantly repressed intraregional trade in South Asia. Our estimates indicate that the member countries could increase regional trade by 20 percent if they eliminated black markets in currencies. Thus, one of the policy options that members could consider for the long run is the creation of a currency union in the region.

We also find that political interaction and cultural similarity are important for regional trade in South Asia. A close look at trade and political relations between India and her neighbors shows that net political cooperation and bilateral trade are highly and positively correlated in the region. Political cooperation not only determines trade flows, however, but also depends on them. If SAPTA members could, despite political tensions, open up their economies for each other's products and for foreign investment, economic and political relations could work interactively to benefit regional integration as well.

Cultural factors also play a significant role in determining trade flows. These are factors that underlie trade and other economic relationships and can make success more durable if economic policy is conducive and political relations develop in a cooperative fashion.

\section{Acknowledgement}

For comments, we thank Susan Randolph and the participants in a session at the Southern Economics Association Conference where this paper was presented in November 2001.

Received 11 January 2002, Accepted 16 August 2002

\section{References}

Ahmed, I. (1996), State, Nation and Ethnicity in Contemporary South Asia. London; New York: Pinter Publishers. 
Anderson, J. (1979), "A Theoretical Foundation for the Gravity Equation.” American Economic Review, 69 (1), 106-116.

Bergstrand, J. (1985), "The Gravity Equation in International Trade: Some Microeconomic Foundations and Empirical Evidence." Review of Economics and Statistics. 67(2), 474 $-481$.

Chenery, H.B. and Syrquin, M. (1975), Patterns of Development 1950-1970, Oxford: University Press.

Deardorff, A. (1997), "Determinants of Bilateral Trade: Does Gravity Work in a Classical World?" in Frankel, J. eds. Regionalization of the World Economy, Chicago: Chicago University Press.

Fitzpatrick (1986), Direct Line Distances; International Edition, Scarecrow Press, Metuchen, NJ.

Frankel, J, Stein, E. and Wei, S. (1995) "Trading Blocs and the Americas: The Natural, the Unnatural, and the Supernatural." Journal of Development Economics, 47(2), 61-96.

Frankel, J, Stein, E. and Wei, S. (1997) Regional Trading Blocs in the World Economic System, Institute for International Economics, Washington, D.C.

Goldstein, J. (1992), "A Conflict-Cooperation Scale for WEIS Events Data" Journal of Conflict Resolution, 36(2), 369-385.

Helpman, E. and Krugman, P. (1985), Market Structure and Foreign Trade, Cambridge, MA: MIT Press.

Hewitt, V. (1997), "The States of South Asia Bilateral Relations" in The New International Politics of South Asia, Manchester University Press.

IMF (1997), Government Financial Statistics Yearbook, Washington D.C.

KEDS (1999), Kansas Events Data System, Department of Political Science, University of Kansas.

Larue, B. and Mutunga, J. (1993), "The Gravity Equation, Market Size, and Black Market Exchange Rates", International Economic Journal, 7(2), 61-75.

Linnenman, H. (1966), An Econometric Study of International Trade Flows, Amsterdam: North Holland.

Pollins, B (1989), "Conflict, Cooperation, and Commerce: The Effect of International Political Interactions on Bilateral Trade Flows", American Journal of Political Science, 33(3), 737-761

Tinbergen, (1962), Shaping the World Economy: Suggestions for an International Economic Policy, New York: The Twentieth Century Fund.

World Event Interaction Survey (WEIS), (1993), Coding Manual. Department of Political Science, USA Naval Academy, MD. 
Appendix I.

Conflict and Cooperation Scale: Weight for WEIS Events

\begin{tabular}{clcc}
\hline Event & \multicolumn{1}{c}{ Description } & Weight & $\begin{array}{c}\text { Standard } \\
\text { Deviation }\end{array}$ \\
\hline 223 & Military Attack & -10.0 & 0.0 \\
211 & Seize position or possession & -9.2 & 0.7 \\
222 & Nonmilitary destruction/injury & -8.7 & 0.5 \\
221 & Noninjury destructive action & -8.3 & 0.6 \\
182 & Armed forced mobilization, exercise, display; military build up & -7.6 & 1.2 \\
195 & Break diplomatic relations & -7.0 & 1.3 \\
173 & Threat with force specified & -7.0 & 1.1 \\
174 & Ultimatum; threat with negative sanction and time limit & -6.9 & 1.4 \\
172 & Threat with specific negative nonmilitary sanction & -5.8 & 1.9 \\
193 & Reduce or cutoff aid or assistance; act to punish/deprive & -5.6 & 1.4 \\
181 & Nonmilitary demonstration, walk out on & -5.2 & 2.1 \\
201 & Order person or personnel out of country & -5.0 & 1.7 \\
202 & Expert organization or group & -4.9 & 1.4 \\
150 & Issue order or command, insist, demand compliance & -4.9 & 1.7 \\
171 & Threat without specific negative sanction stated & -4.4 & 1.5 \\
212 & Detain or arrest person(s) & -4.4 & 2.3 \\
192 & Reduce routine international activity; recall officials & -4.1 & 1.2 \\
112 & Refuse; oppose; refuse allow & -4.0 & 1.5 \\
111 & Turn down proposal; reject protest, demand, threat & -4.0 & 1.5 \\
194 & Halt negotiation & -3.8 & 0.9 \\
122 & Denounce; denigrate; abuse & -3.4 & 1.1 \\
160 & Give warning & -3.0 & 1.3 \\
132 & Issue formal complaint or protest & -2.4 & 0.9 \\
121 & Charge; criticize; blame; disapprove & -2.2 & 1.3 \\
191 & Cancel or postpone planned event & -2.2 & 1.5 \\
131 & Make complaint (not formal) & -1.9 & 0.6 \\
063 & Grant asylum & -1.1 & 2.5 \\
142 & Deny an attributed policy, action, role or position & -1.1 & 1.0 \\
141 & Deny an accusation & -0.9 & 1.3 \\
023 & Comment on situation & -0.2 & 0.5 \\
\hline & & & \\
& & &
\end{tabular}


Appendix I.(contd.)

Conflict and Cooperation Scale: Weight for WEIS Events

\begin{tabular}{clcc}
\hline Event & \multicolumn{1}{c}{ Description } & Weight & $\begin{array}{c}\text { Standard } \\
\text { Deviation }\end{array}$ \\
\hline 102 & Urge or suggest action or policy & -0.1 & 1.5 \\
021 & Explicit decline to comment & -0.1 & 0.6 \\
094 & Request action; call for & -0.1 & 1.0 \\
025 & Explain or state policy; state future position & 0.0 & 0.0 \\
091 & Ask for information & 0.1 & 0.4 \\
011 & Surrender, yield to order, submit to arrest & 0.6 & 7.2 \\
012 & Yield position; retreat; evacuate & 0.6 & 6.6 \\
031 & Meet with; send note & 1.0 & 0.9 \\
095 & Entreat; plead; appeal to ; beg & 1.2 & 1.8 \\
101 & Offer proposal & 1.5 & 1.9 \\
061 & Express regret; apologize & 1.8 & 1.5 \\
032 & Visit; go to & 1.9 & 2.4 \\
066 & Release and/or return persons or property & 1.9 & 2.7 \\
013 & Admit wrongdoing; apologize, retract statement & 2.0 & 2.2 \\
062 & Give state invitation & 2.5 & 2.7 \\
054 & Assure; reassure & 2.8 & 2.2 \\
033 & Receive visit; host & 2.8 & 3.0 \\
065 & Suspend sanctions; end punishment; call truce & 2.9 & 3.6 \\
082 & Agree to future action or procedure, to meet, or to negotiate & 3.0 & 2.5 \\
092 & Ask for policy assistance & 3.4 & 1.1 \\
093 & Ask for material assistance & 3.4 & 2.4 \\
041 & Praise, hail, applaud, extend condolences & 3.4 & 2.1 \\
042 & Endorse others policy or position; give verbal support & 3.6 & 1.8 \\
053 & Promise other future support & 4.5 & 1.6 \\
051 & Promise own policy support & 4.5 & 1.7 \\
052 & Promise material support & 5.2 & 1.5 \\
064 & Grant privilege; diplomatic recognition; de facto relations & 5.4 & 1.4 \\
073 & Give other assistance & 6.5 & 1.9 \\
081 & Make substantive agreement & 6.5 & 1.4 \\
071 & Extend economic aid; give, buy, sell, loan, borrow & 7.4 & 1.0 \\
072 & Extend military assistance & 8.3 & 0.9 \\
\hline & & & \\
\hline
\end{tabular}

Source: Goldsteien (1992) 